\title{
Ornamental Plant Response to Phosphate Addition and Inoculation with Am Fungi and its Application in Restoring Polluted Soils
}

\author{
V.Divya Rao*, Y.Avasn. Maruthi \\ Department of Environmental Studies, GITAM Institute of Science, GITAM University, Visakhapatnam 530045,Andhra Pradesh \\ *Corresponding Author: divya.vuyuru@gmail.com
}

Copyright (C) 2013 Horizon Research Publishing All rights reserved.

\begin{abstract}
Visakhapatnam is famously known as the "city of destiny". Rapid industrialization and urbanization have increased the levels of pollution in soils causing insignificant loss of ancient plant species and soil microflora.AM fungal association is present with almost all the plants. Residential and commercial area were taken into consideration and percentage AM colonization was identified. Two ornamental plant species were taken namely S. scutellarioides and I.herbistii. . Glomus $\mathrm{sp}$ and Acaulospora $\mathrm{sp}$ showed maximum colonization. There was increase in the levels of Phosphate with S. scutellarioides plant species and about $72 \%$ of colonization was seen in both the residential and commercial sites. The Phosphate levels were not upto the mark with I.herbstii species where colonization also resulted the same with about $32 \%$ in both the residential and commercial sites.
\end{abstract}

Keywords Arbuscular Mycorrhizal fungi, Ornamental Plants, Phosphate

\section{Introduction}

The limiting factor for plant growth is basically unavailability of nutrients which can be enriched by change in plant community. In generally, plants get adapted to infertile conditions in aged soils due to which plants become unable to survive. In turn, missing plant species can cause a decline in the abundance of soil organisms that require them as host (Perry et al.,1980), which has implication for the community and ecosystem processes that these soil organisms mediate. In restoring soils, this kind of mutualistic associations is essential for the functional restoration of disturbed soil systems (Harris et al.,2005; Perry and Amaranthus,1990; Renker et al.,2004; Whisenant,1999; Young et al.,2005) such as polluted soils.

Indiscriminate application of synthetic fertilizers not only causes detrimental environmental effects due to leaching, but also increases the global warming potential by $2 \%$ through their manufacturing process, which could be decreased markedly with nutrient recycling (Gilbert et al., 2011). Recycling nutrients from organic wastes, such as sludge, provides an opportunity to save energy and improve sustainability in agriculture (M.F. Seleiman et al., 2013).

Arbuscular Mycorrhizae, particularly play a fundamental role in development of vegetation in polluted soils. AM will also be limited by the availability of propagules (i.e. spores, hyphae, colonized roots) following the soil disturbance that occurs in the removal of vegetation for cultivation (Jasper et al., 1991; Johnson et al.,1991; Perry et al., 1989).

Arbuscular mycorrhizae (AM) contribute to plant growth and nutrient uptake, specially $\mathrm{P}$ (Smith and Gianinazzi-Pearson, 1988). Contribution can be a direct effect through an exploration of a larger volume of soil and/or a hyphal access to soil $\mathrm{P}$ pools not available to plants (Koide, 1991; Li et al., 1991; Jayachandran et al., 1992). Some authors even assert that AM mycelia may have P mineralizing activity (Jayachandran et al., 1992; Tarafdar and Marshner, 1994). Arbuscular mycorrhizal (AM) fungi are the ubiquitous in soil ecosystem and widespread symbioses occurring in terrestrial plant (Smith and Smith, 2011). Around $90 \%$ of land plants distributed in all major biomes are potentially mycorrhizal (Smith and Read, 2008; Smith et al., 2010; Smith and Smith, 2011). The remaining $10 \%$ of plants, including Chenopodiaceae and Brassicaceae, are considered non-mycorrhizal. AM fungi can improve the nutritional status of the host plant through uptake of mineral nutrients, especially $\mathrm{P}$, based on extensive mycelium in the soil (M.F. Seleiman et al.,2013).

It was predicted that the Phosphate fertilizer residues limit the enhancement of vegetation and mutual symbiosis of mycorrhizae with the plants of residential as well as commercial areas of Visakhapatnam, Andhra Pradesh. To test this prediction, a pot study was conducted in a green house with and without AM inoculums and response of the plants with Phosphate addition.

\section{Materials and Methods}




\subsection{Experimental Design}

This work was designed the experimental setup considering three factors: with and without AM inoculums (control) in residential and commercial sites, Phosphate addition and two ornamental plant species. Pots, each containing one plant were laid in the green house in two blocks as residential and commercial blocks for about two months.

The two native plants species selected were Solenostemon scutellarioides and Iresine herbistii . S.scutellarioides and I.herbistii are commonly known as Coleus and Blood leaf respectively. Though there are evidences that AM colonization in different Coleus plant species (Sailo and Bagyaraj, 2005) where no specific records of any fungal association is found in Bloodleaf plant as they belong to Amaranthaceae species. These plants were planted through the process of vegetation propagation.

In this study, soil samples were collected from the residential as well as commercial sites in and were placed in glasshouse for about 90 days and watered. A ratio of 1:3 ratio where one part was the collected soil samples and the rest three parts were sterilized sand soil (sterilized at $80^{\circ} \mathrm{C}$ forlhour).pots of $8 \mathrm{~cm} \times 8 \mathrm{~cm} \times 15 \mathrm{~cm}$ (depth).Additional plant nutrients along with Phosphates were given to both AM inoculated and uninoculated plants in the form of Hoagland's solution (absence of Phosphates) (Hoagland.1950).This solution was given to the plants for every 15 days and were hand watered (with deionised water) every day to prevent mycorrhizal contamination of uninoculated pots. Dead plants were replaced in the first two weeks.

\subsection{Response Variables}

The two plants species were harvested for 12 weeks and soil samples were collected randomly foe every $15^{\text {th }}$ day. All the physico-chemical and microbial parameters were analyzed(Table 1, Table 1.1, Table2 \& Table2.1) .Soil pH, Nitrogen, Potassium, Phosphates and Organic Carbon were analyzed particularly as there was only negligible change in the values. Soil $\mathrm{pH}$ was measured using the $\mathrm{pH}$ meter ,Nitrogen was measured with Kjedahl apparatus, Phosphates and Potassium were measured using spectrometer. These values of $\mathrm{pH}$, Nitrogen, Potassium, Phosphates and Organic Carbon were measured with interval of 15 days.

The soil samples were taken for every 15 days and the sporulation was assessed. $100 \mathrm{~g}$ of soil sample was collected from the test pots for every 15 days, mixed with $1000 \mathrm{ml}$ of tap water and stirred well. After a minute they filtered in sieves arranged in descending order of Mesh size $(250 \mathrm{~cm}-37 \mathrm{~cm})$ order and filtered in filter paper. The filtered paper was viewed under stereolight microscope. After 12 week set up the fine roots of the plants were washed and sub sampled. The fine roots were then washed or cleared with
$10 \%(\mathrm{w} / \mathrm{v})$ Potassium Hydroxide at $55^{\circ} \mathrm{C}$ overnight and then stained 1\% Trypan blue (v/v) Phillips and Hayman (1970) solution for 1 hour before being transferred to a solution of Lactoglycerol (Rodrigues, B, F., Muthukumar, T., 2009).

\subsection{Statistical Analysis}

Characterization of $\mathrm{pH}$, Soil Organic Carbon, Total Nitrogen, Phosphates and Potassium were subjected to ANOVA using the Minitab 14 statistical package (Minitab, 2007).

\section{Results}

\subsection{S.scutellarioides}

There was no significant effect on the physico-chemical parameters of the test soil throughout the study period except with that of soil $\mathrm{pH}$, Nitrogen, Potassium, Phosphates and Organic Carbon in both residential and commercial sites(Fig $1 \&$ Fig 1.1). An increase in the levels of Phosphates was definitely seen in the test soil samples of both the residential and commercial soils along with a comparative increase in soil $\mathrm{pH}$, Nitrogen, Potassium and decrease in Organic Carbon . The colonization of AM was also seen. The growth in the plant species was also identified as compared to that of control soils in all the test plants. Residential area where the colonization is more in S.scutellarioides in a range $40 \%$ to $70 \%$ as compared to the control soils or without AM fungi inoculums (Fig 3). Commercial zone showed a colonization percentage of $45 \%$ to $78 \%$ with control soils or without AM fungal innoculum which recorded less (Fig 3).
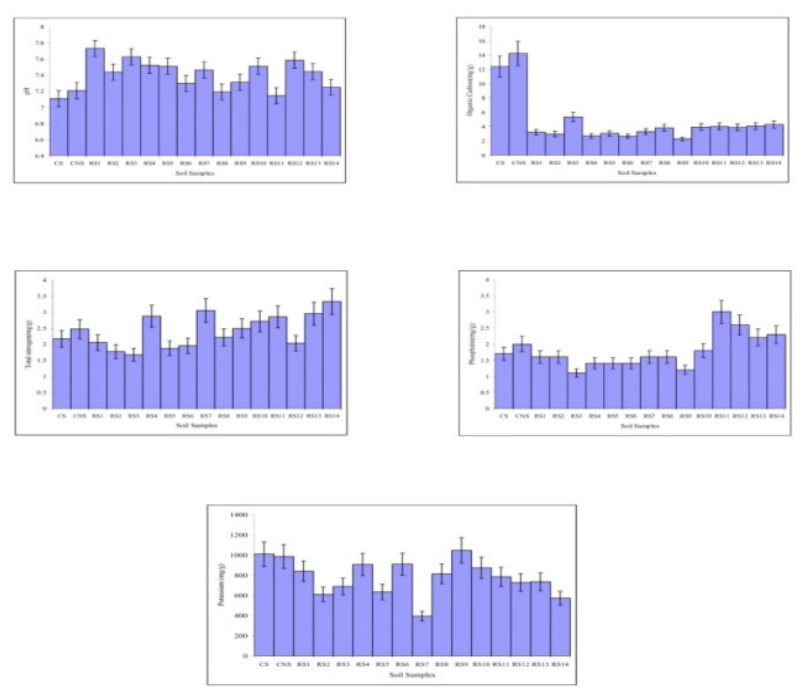

Figure 1. Statistical variation in $\mathrm{pH}$, Organic Carbon, Total Nitrogen, Phosphates and Potassium in test soil samples of S. scutellarioides in Residential Zone 

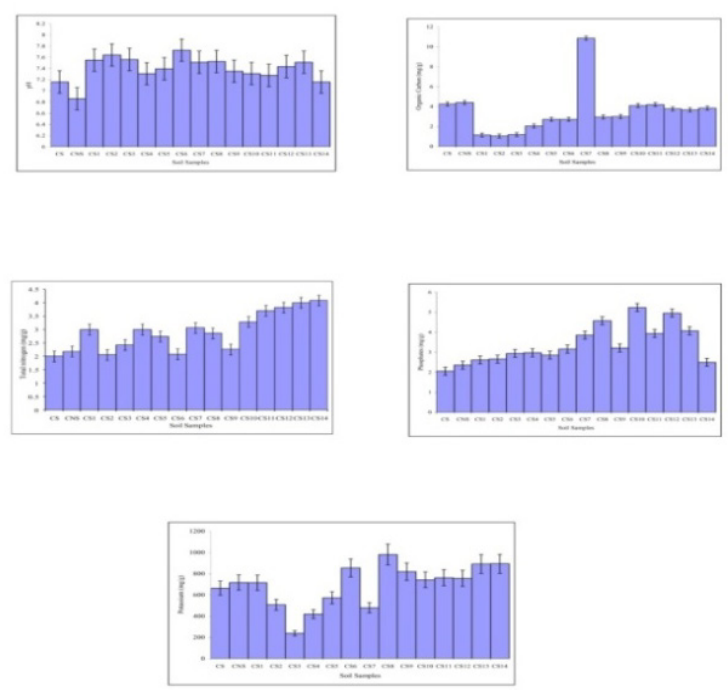

Figure 1.1. Statistical variation in $\mathrm{pH}$, Organic Carbon, Total Nitrogen, Phosphates and Potassium in test soil samples of S. scutellarioides in Commercial Zone

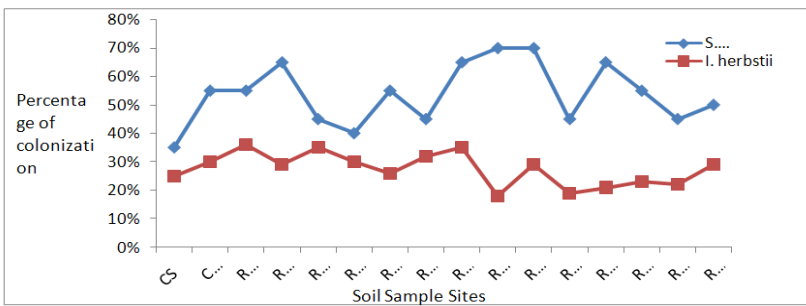

Figure 3. Percentage of fungal colonization in roots of rhizosphere soil of two test plants in Residential zone

\subsection{I.herbistii}
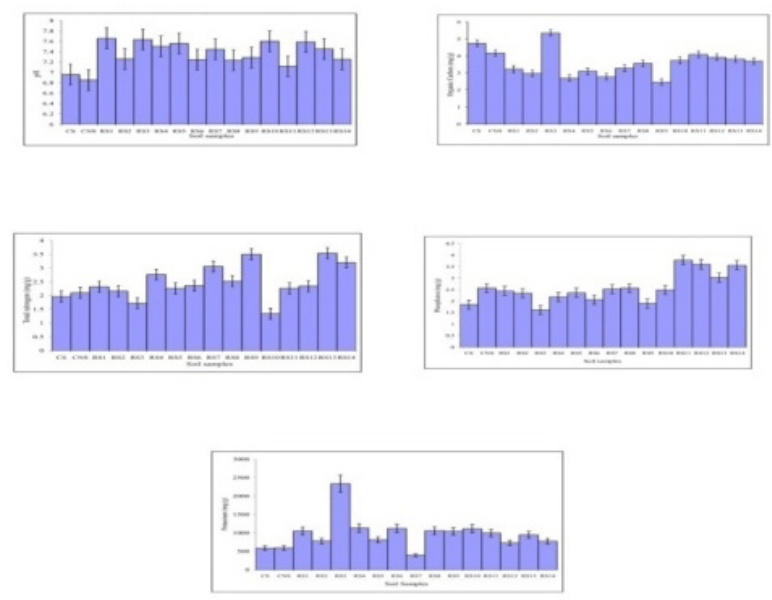

Figure 2. Statistical variation in $\mathrm{pH}$, Organic Carbon, Total Nitrogen, Phosphates and Potassium in test soil samples of I.herbstii in Residential Zone

Though the test soil samples with this plant species also did not show any change in the physico-chemical parameters, there was even no increase in the Phosphates levels in the test soil samples of residential and commercial sites (Fig $2 \&$ Fig 2.1). This plant species did not show any
AM colonization throught the study period and the plant growth was also not significant. The colonization in I.herbstii was less in residential area with a array of $22 \%$ to $36 \%$ with comparison to control soil or without AM fungi inoculums (control) (Fig 4). Commercial zone showed a colonization percentage of $18 \%$ to $32 \%$ with control soils or without AM fungal innoculum with also recorded less with this plant species (Fig 4).
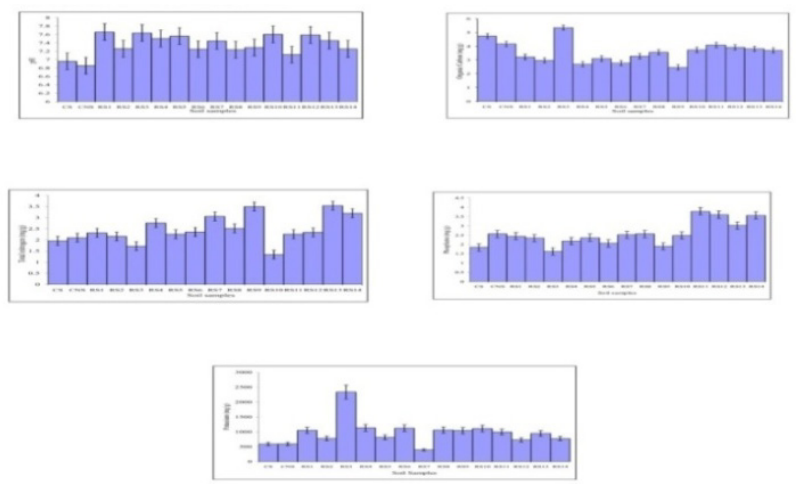

Figure 2.1. Statistical variation in $\mathrm{pH}$, Organic Carbon, Total Nitrogen, Phosphates and Potassium in test soil samples of I.herbstii in Commercial Zone

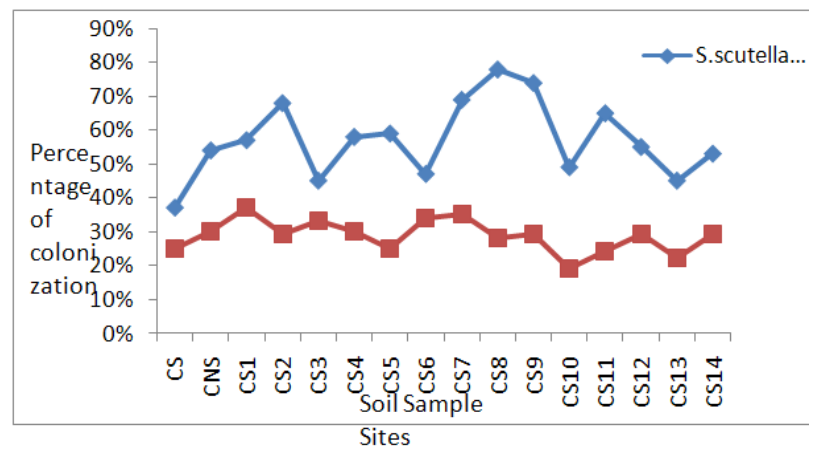

Figure 4. Percentage of fungal colonization in roots of rhizosphere soil of two test plants in Commercial zone

\subsection{Colonization of the Test Soil Samples}

Colonization of AM fungi varied from site to site and zone to zone. Though there was difference between the sampling sites but both the zones namely residential and commercial zone, the number spores of Glomus sp and Acaulospora sp were maximum and found were more in number with S.scutellarioides where I.herbstii showed very less spore count.

\subsection{Morphology of the Test Plants}

During the experimental work the plants grown represents the status of colonization and sporulation in the roots by AM fungi. The leaves of S.scutellarioides showed large surface area which represent the plant species had a good range of photosynthesis. S.scutellarioides showed good results in both zones where leaves of I.herbstii had very less surface area in both zones when compared with other test 
plants which showed decreased process of photosynthesis.

\section{Discussion \& Conclusion}

Analysis physico-chemical and microbial parameters of the test soil samples of residential and commercial resulted in insufficiency of vital mineral nutrients like Nitrogen, Phosphate and Potassium. As focused by Kumar et al (2010) that in the process of $\mathrm{AM}$ root colonization $\mathrm{pH}$ factor plays a vivid role and in trivial acidic condition the $\mathrm{pH}$ shows no problem for the growth of the plant. The $\mathrm{pH}$ in soils which showed slightly acidic values were helpful for sporulation of Glomus sp where as acidic $\mathrm{pH}$ showed the sporulation of Acaluspora sp as studied by Porter et al (1987), Wang et al (1993) and Gia and Liu (2003).

The concentration of Nitrogen, Potassium and Phosphate was increased during the study period .Zhang et al (2003) suggested that a drop off soil $\mathrm{pH}$, Electrical Conductivity, Organic Carbon and boosting in soil vital nutrients like Nitrogen, Potassium and Phosphate may be due to increased concentrations of Organic acids because of AM colonization. As stated by Neuman and George (2004) and Subramanian et al (2006) AMF spore production can be more or less on application of Phosphorous rich fertilizers. On the other hand Hui Jiao et al (2011) stated that there is a reduction in AMF sporulation on application of fertilizers.

In increased Phosphorous levels there is a decline in the spore number as well as root colonization due to less exudation (Ratnayake et al .,1978 and Graham et al., 1981).But the reduction in soil Phosphorous may be one of the reason for AM colonization which hamper the hyphal growth. Nitrogen results a decrease in the AM colonization but it helps to increase the number of spores in the rhizosphere area of the soil (Redhead, 1975).Muthukumar et al (1998) described that Potassium also showed a negative relation with the AM colonization with good sporulation in rhizosphere zone of the plant.

Among all the two plant species one of the species namely S.scutellarioides responded well and illustrated good amount of spores with effective root colonization whereas the second species as I. herbstii which belong to the family Amaranthaceae, having less or no capability to have bonding with AM fungi as stated by Sheraz Mahdi et al (2010).The above result suggested that the two plant species can be used for land restoration, in less fertilized soils etc as they have shown best colonization with good plant growth.

\section{Acknowledgements}

All authors are thankful to management of GITAM University for providing laboratory facilities.

\section{REFERENCES}

[1] Gai J P, Liu R J( 2003). Effects of soil factors on AMF in the rhizosphere of wild plants. Chin J Appl Ecol 14,18-22 (in Chinese, with an English abstract).

[2] Gilbert P, Thornley P, Riche A (2011). The influence of organic and inorganic fertiliser application rates on UK biomass crop sustainability. Biomass Bioenerg. 35, 1170-1181.

[3] Graham J H, Leonard R T, Menge J A (1981).Membrane mediated decrease in root exudation responsible for phosphorus inhibition of vesicular-arbuscular mycorrhizal formation. New Phytol.91,683-690.

[4] Harris J A, Grogan P, Hobbs R J (2005). Restoration ecology and the role of soil biodiversity. In: Bardgett, R.D., Usher, M.B., Hopkins, D.W. (Eds.), Biological Diversity and Function in Soils. Cambridge University Press, Cambridge, pp. 319-342.

[5] Phillips, J, M., Hayman, D, S., (1970). Improved procedures for clearing roots and staining parasitic and vesicualar-arbuscular mycorrhizal fungi for rapid assessment of infection. Trans. Br. Mycol. Soc. 55,158-161.

[6] Hoagland D R, Arnon D I (1950). The water culture method for growing plants without soil. California Agricultural Experiment Station Circular -347.

[7] Hui Jiao, Yinglong Chen, Xiangui Lin, Runjin Liu (2011).Diversity of Arbuscular Mycorrhizal Fungi in green house soils continuously planted to watermelon in North China.Mycorrhizae:21,681-688.

[8] Jasper D A, Abbott L K, Robson A D (1991). The effect of soil disturbance on vesicular-arbuscular mycorrhizal fungi, in soils from different vegetation types. New Phytol. 118, 471-476.

[9] Jayachandran K, Schwab A P, Hetrick B A(1992). Mineralization of organic phosphorus by vesicular-Arbuscul ar mycorrhizal fungi. Soil Biol. Biochem. 24, 897-903.

[10] Johnson N C ,Zak D R,Tilman D,Pfleger F L(1991).Dynami cs of vesicular Arbuscular mycorrhizae during old-fieldsuccession.Oecologia86,349-358.

[11] Koide R T (1991). Nutrient supply. New Phytol. 117, 365-386.

[12] Kumar A, Mangla C , Aggarwal A, Prakash V (2010).Arbbu scular mycorrhizal fungal dynamics in the rhizosphere soil of five medicinal plant

species.Middle-East.J .Sci.Res.6,281-288.

[13] Li X.L, George E, Marshner H (1991). Extension of the phosphorus depletion zone in VA-mycorrhizal white clover in a calcareous soil. Plant Soil 136, 41-48.

[14] Mahmoud F. Seleiman, Arja Santanen, Jouko Kleemola, Frederick L. Stoddard, Pirjo S.A. Mäkelä(2013). Improved sustainability of feedstock production with sludge and interacting mycorrhiza. Chemosphere.

[15] Muthukumar T, Udaiyan K, Manian S (1998).Within-season variations of VA mycorrhizal fungi in relation to soil factors in nutrient deficient soils. New Bot.25,117-135.

[16] Neumann E, George E (2004). Colonisation with the 
Arbuscular mycorrhizal fungus Glomus mosseae (Nicol. \& Gerd.) enhanced phosphorus uptake from dry soil in Sorghum bicolor (L.). PlantSoil 261,245-255.

[17] Perry D A, Amaranthus M P (1990). The plant-soil bootstrap: microorganisms and reclamation of degraded ecosystems .In:Berger,J.J.(Ed.),Environmental Restoration: Science and Strategies for Restoring the Earth. Island Press, Washington, pp. 94-102.

[18] Perry D A, Amaranthus M.P, Borchers J G, Borchers S L, Brainerd $\mathrm{R}$ E(1989). Bootstrapping in ecosystems. Bioscience 39, 230-237.

[19] Porter W M, Robson A D, Abbott L K.(1987). Field survey of the distribution of vesicular- arbuscular mycorrhizal fungi in relation to soil pH. J Appl Ecol 24,659-662.

[20] Ratnayake M, Leonard R T, Mengo J A(1978).Root exudates in relation to supply of phosphorus and its possible relevance to mycorrhiza. New Phytol.81,543-552.

[21] Redhead J F (1975) .Endotrophic mycorrhizas in Nigeria: Some aspects of the ecology of endotrophic mycorrhizal association of Khaya grandifolia.In: Endomycorrhiza (F E Sanders, Mosse B and Tinker P B, eds).Academic press,London..447-459.

[22] Renker C, Zobel M,Öpik M, Allen M F ,Allen E B ,Vosátka M ,Rydlová J, Buscot F( 2004). Structure, dynamics, and restoration of plant communities: do arbuscular mycorrhizae matter? In: Temperton, V.M., Hobbs, R.J., Nuttle,T.,Halle,S.(Eds.),AssemblyRulesandRestorationEcolo gy:Bridging the Gap between Theory and Practice. Island Press, Washington, pp.189-229.

[23] Rodrigues B F, Muthukumar T (2009).Arbuscular Mycorrhizae Of Goa- A Manual Of Identification Protocols.Published by Goa University,Goa-India.First Edition, 1,7-38.

[24] Sailo G L and Bagyaraj D J(2005).Influence of different AM fungi on the growth, nutrition and forskolin content of Coleus forskolii. Mycol. Res .109,795-798.

[25] Sheraz Mahid S, Hassan G I, Samoon S A, Rathe H A,
Showkat Dar A, Zehra B (2010). Bio- Fertilizers in organic agriculture. Journal of Phytology 2(10),42-54.

[26] Smith S E, Christophersen H M, Pope S, Smith F A (2010). Arsenic uptake and toxicity in plants: integrating mycorrhizal influences. Plant Soil 327, 1-21.

[27] Smith S E, Read D J (2008). Mycorrhizal Symbiosis. Academic Press, New York.

[28] Smith S E, Smith F A. (2011). Roles of arbuscular mycorrhizas in plant nutrition and growth: new paradigms from cellular to ecosystem scales. Annu. Rev. Plant Biol. 62, $227-250$.

[29] Smith S E ,Gianinazzi-Pearson V (1988).Physiological interactions between symbionts in vesicular-arbuscular mycorrhizal plants. Ann. Rev. Plant Physiol. Plant Mol. Biol.39, 221-244.

[30] Subramanian K S, Santhanakrishnan P, Balasubramanian P (2006).Responses of field grown tomato plants to arbuscular mycorrhizal fungal colonization under varying intensities of drought stress. Sci Hortic .107,245-253.

[31] Tarafdar J C, Marshner H (1994). Phosphatase activity in the rhizosphere of VA mycorrhizal wheat supplied with inorganic and organic phosphorus. Soil Biol. Biochem. 26, 387-395.

[32] Wang G M, Stribley D P, Tinker P B, Walker C (1993). Effects of $\mathrm{pH}$ on arbuscular mycorrhiza I. Field observations on the long-term liming experiments at Rothamsted and Woburn. New Phytol 124,465-472.

[33] Whisenant S G (1999). Repairing Damaged Wildlands: A Process-Orientated, Landscape-Scale Approach. Cambridge University Press, Cambridge.

[34] Young T P, Petersen D A, Clary J J (2005). The ecology of restoration: historical links, emerging issues and unexplored realms. Ecol. Lett. 8, 662-673.

[35] Zhang Y F, Feng G, Li, X( 2003). The effect of Arbuscular mycorrhizal fungi on the components and concentration of organic acids in the exudates of mycorrhizal red clover. Acta.Ecol.Sin.23,30-37.cnki:ISSN:1000-0933.0.2003-01-00 4. 